\title{
Postmarketing Surveillance of the Safety and Effectiveness of Etanercept in Japan
}

\author{
TAKAO KOIKE, MASAYOSHI HARIGAI, SHIGEKO INOKUMA, KAZUHIKO INOUE, NAOKI ISHIGURO, \\ JUNNOSUKE RYU, TSUTOMU TAKEUCHI, YOSHIYA TANAKA, HISASHI YAMANAKA, KOICHI FUJII, \\ BRUCE FREUNDLICH, and MICHIO SUZUKAWA
}

\begin{abstract}
Objective. Postmarketing surveillance (PMS) was conducted evaluating safety and effectiveness of etanercept $\left(\mathrm{ETN}\right.$; Enbrel $\left.{ }^{\circledR}\right)$ in Japan, following all patients with rheumatoid arthritis (RA) during the conditional approval period of ETN.

Methods. Registration of patients from 1,334 medical sites was conducted between March 2005 and April 2007. Patients were followed for 24 weeks; data regarding patients' background, safety, and effectiveness was recorded centrally. Adverse events (AE) and adverse drug reactions (ADR) were coded using the Medical Dictionary for Regulatory Activities. Effectiveness was measured using the Disease Activity Score 28 (DAS28).

Results. Of 14,369 patients registered, data collection and evaluation for 7,091 patients by March 2006 is reported. At least $1 \mathrm{AE}$ was observed for 2,173 patients (30.6\%); 60\% of AE occurred within 8 weeks of starting ETN. Most frequent AE were injection site reaction $(\mathrm{n}=377,5.3 \%)$ and rash $(\mathrm{n}=228,3.2 \%)$. Serious AE occurred in 403 patients $(5.7 \%)$; most frequent were pneumonia $(\mathrm{n}=$ $59,0.8 \%)$ and interstitial lung disease $(n=42,0.6 \%)$. Pneumonia was the most common specifically important ADR $(\mathrm{n}=102,1.4 \%)$. Mean baseline DAS28 was 6.0 , which reduced to 4.4 within 4 weeks, and to 3.9 within 24 weeks. The proportion of patients having good or moderate EULAR response measured by DAS28 was $84.1 \%$ at Week 24 . Effectiveness rates were more favorable in patients concomitantly using methotrexate. Good or moderate EULAR response rate among patients switched from infliximab was $84.9 \%$.

Conclusion. This extensive observational trial, including all patients with RA in Japan taking ETN, found ETN to be both effective and well tolerated by Japanese patients with RA. Trial registration: clinicaltrials.gov identifier NCT00503503. (First Release April 1 2009; J Rheumatol 2009;36:898-906; doi:10.3899/jrheum.080791)
\end{abstract}

\section{Key Indexing Terms: RHEUMATOID ARTHRITIS JAPAN}

\section{ETANERCEPT EFFICACY}

Phase III clinical trials are intended to evaluate efficacy and safety of new drugs. However, even large well designed Phase III clinical studies may fail to reflect the safety and

From the Japan College of Rheumatology Etanercept Post-Marketing Surveillance Committee; Wyeth K.K., Medical Affairs, Osaka, Japan; and Wyeth Research, Collegeville, Pennsylvania, USA.

Supported by Wyeth; clinical fees were shared by Wyeth K.K. and Takeda Pharmaceutical Company Limited.

T. Koike, MD, PhD, Hokkaido University Graduate School of Medicine; M. Harigai, MD, PhD, Tokyo Medical Dental University Graduate School; S. Inokuma, MD, PhD, Japanese Red Cross Medical Center; K. Inoue, MD, PhD, Tokyo Women's Medical University Medical Center East; N. Ishiguro, MD, PhD, Nagoya University Graduate School of Medicine; J. Ryu, MD, PhD, Nihon University School of Medicine; T. Takeuchi, MD, PhD, Saitama Medical School; Y. Tanaka, MD, PhD, University of Occupational and Environmental Health; H. Yamanaka, MD, $P h D$, Tokyo Women's Medical University; K. Fujii, MD, PhD, Wyeth KK, Medical Affairs; B. Freundlich, MD, Wyeth Research, Collegeville, PA; M. Suzukawa, MD, PhD, Wyeth KK, Medical Affairs.

Address reprint requests to Dr. B. Freundlich, Wyeth Pharmaceuticals Inc., 500 Arcola Road, E-4340, Collegeville, PA 9426-3930, USA.

E-mail:FREUNDB@wyeth.com

Accepted for publication December 12, 2008. effectiveness of new drugs in the real world. The goal of postmarketing surveillance (PMS) is to monitor ongoing safety and effectiveness of marketed drugs by identifying adverse events (AE), adverse drug reactions (ADR), and effectiveness. Risks and benefits associated with taking a particular drug are reassessed based on information learned after the drug is marketed, and ways to appropriately balance the risks and benefits are then recommended. In the US, PMS is overseen by the Food and Drug Administration, operating through a system called Medwatch ${ }^{1}$, while in Canada, a division of Health Canada, the Marketed Health Products Directorate, coordinates it ${ }^{2}$. In Japan, the Pharmaceutical and Medical Device Agency (PMDA) is the corresponding regulatory body.

Etanercept (ETN; Enbrel $\left.{ }^{\circledR}\right)$ is a biologic agent used to treat patients with rheumatoid arthritis (RA) who have inadequately responded to at least one other disease modifying antirheumatic drug (DMARD), often including methotrexate $(\mathrm{MTX})^{3,4}$. In the $\mathrm{ERA}^{5}$ (Early Rheumatoid Arthritis) and COMET $^{6}$ (Combination of Methotrexate and Etanercept in 
Active Early Rheumatoid Arthritis) trials MTX- and DMARD-naive patients were treated. ETN is a fully human soluble receptor Fc fusion protein that binds to tumor necrosis factor (TNF) and blocks its interaction with cell-surface TNF receptors. In Japan, the use of ETN for RA was conditionally approved in March 2005. ETN could be used only when the medical institution fulfilled the institution selection criteria defined by the PMDA. All physicians prescribing ETN and patients using ETN were registered in the All Cases Surveillance program. A further condition of approval was the collection of AE of special interest, specifically tuberculosis (TB), opportunistic infection, interstitial lung disease, malignancy, demyelinating diseases, and congestive heart failure.

This PMS registered all patients treated with ETN in Japan. Information about onset, frequency, severity, and other details of AE, ADR, and other factors considered related to safety and effectiveness was collected. The primary objective of surveillance was to evaluate the real-world safety and effectiveness of ETN for all patients receiving it in Japan after its introduction into the market. The PMS study for ETN began in March 2005 and registered more than 14,000 patients in 2 years. This report presents safety and effectiveness results from the 7,091 patients registered between March 2005 and March 2006 who completed 24 weeks of ETN treatment and observation.

\section{MATERIALS AND METHODS}

There were 1,334 sites participating in the study (trial registration identifier NCT00503503); every RA patient treated with ETN in Japan between March 2005 and March 2006 was tracked for the first 24 weeks of treatment. Patient eligibility for treatment with ETN was based on the Japan College of Rheumatology treatment guidelines ${ }^{7}$. Patients were those with RA who had not been successfully treated with other conventional DMARD (MTX, salazosulfapyridine, bucillamine) and who had $\geq 6$ tender joints, $\geq 6$ swollen joints, erythrocyte sedimentation rate $(\mathrm{ESR}) \geq 28 \mathrm{~mm} / \mathrm{h}$, or C-reactive protein $(\mathrm{CRP}) \geq 2.0 \mathrm{mg} / \mathrm{dl}$. They also met the following criteria: a low risk for opportunistic infections as defined by a white blood cell count $\geq 4,000 / \mathrm{mm}^{3}$, peripheral blood lymphocytes $\geq 1,000 / \mathrm{mm}^{3}$, and negative serum B-D-glucan. Mandatory chest radiographs and tuberculin tests were also obtained prior to the initiation of ETN. ETN (10 mg or $25 \mathrm{mg}$ ) was administered by a single subcutaneous injection twice a week. Patients had training for self-injection over a 1-month period and were subsequently allowed to proceed with self-injection after learning the skills.

Data recording. The PMS protocol was reviewed and approved by the Ministry of Health, Labor and Welfare. Registration was conducted centrally at the time patients started ETN, and data collection was performed through an electronic data capture system, the Internet, or hardcopy case report forms. Medical representatives from Wyeth and Takeda Pharmaceutical Company visited sites periodically to collect additional data as required. Information on age, sex, comorbidity, Steinbrocker radiographic stage $^{8}$, Steinbrocker functional class, duration of RA, history of smoking, previous and concomitant use of steroids, and concomitant use of DMARD including MTX was collected. ESR and CRP levels were also measured and recorded.

Safety evaluation. All patients were assessed for safety every 2 weeks. Safety evaluation included all events that occurred within 24 weeks of the first dose of ETN and within 30 days of the last dose of ETN. Particular attention was paid to monitoring the occurrence of infections, especially
TB. Safety data were coded with preferred terms from the Medical Dictionary for Regulatory Activities (MedDRA) ${ }^{9}$. Definition of AE (untoward medical events not necessarily causally related to the treatment) and ADR (noxious and unintended responses deemed to be related to the treatment) were based on the ICH Harmonised Tripartite Guideline ${ }^{10}$. Safety information obtained through PMS was evaluated independently by the Japan College of Rheumatology PMS Committee.

Effectiveness evaluation. Effectiveness of treatment was measured by European League Against Rheumatism (EULAR) response criteria ${ }^{11}$ and Disease Activity Score (DAS28) ${ }^{12}$. The DAS28 is a combined index of 28 -joint evaluation, ESR, and pain on visual analog scale. DAS28 was divided into 4 categories: remission $(\leq 2.6)$, low disease activity ( $>2.6$ and $\leq 3.2)$, moderate disease activity $(>3.2$ and $\leq 5.1)$, and high disease activity (> 5.1). Good response was defined as improvement $>1.2$ on the DAS28 from baseline, and a DAS28 score obtained during followup of $\leq 3.2$. Nonresponders were patients with improvement of $\leq 0.6$ or patients with improvement between 0.6 and 1.2 and a DAS28 during followup of $>5.1$. The remaining patients were classified as moderate responders, defined as an improvement on the DAS28 from baseline of between 0.6 and 1.2, and a DAS28 obtained during followup of $\leq 5.1$. Treatment was defined as effective for cases with a moderate or good response. Morning stiffness was measured in addition to DAS28.

Data analysis. The cumulative occurrence rates of AE and ADR were compiled to generate a Kaplan-Meier plot. Missing data values were processed using the last observation carried forward method, except baseline values, which were not carried forward. For example, if the value at Week 4 was missing, the value at Week 8 was present, and all values at Week 12 and thereafter were missing, then the value at Week 8 would be substituted for all the values at Week 12 and thereafter (but the value at Week 4 would remain as missing). Paired sample $t$ tests were used to compare differences between baseline and Weeks 4 and 24, chi-square tests to compare the differences in EULAR response rates, and Cochran-Armitage tests to evaluate trends in response rates.

\section{RESULTS}

Results of the interim analysis of the PMS are presented below. The authors plan to present the results of the final analysis of all 14,369 registered patients when the study is complete.

Patient characteristics. A total of 7,091 patients treated with ETN completed 24 weeks of treatment and observation during the study period (Table 1$)$. A majority $(81 \%, \mathrm{n}=5,746)$ were female. Most patients $(79 \%, \mathrm{n}=5,600)$ were over 50 years of age, and mean patient weight was $53.3 \mathrm{~kg}$ ( $\mathrm{n}=$ $4,455)$. Of total cases, 7,066 cases $(99.6 \%$ correction rate) were treated for RA - the indications that were not RA (25 cases in total) were "malignant RA" (RA with rheumatoid vasculitis, 11 cases), juvenile idiopathic arthritis (5 cases), adult-onset Still's disease (5 cases), pustulotic arthroosteitis (1 case), multicentric reticulohistiocytosis (1 case), Takayasu arteritis (1 case), and sarcoidosis (1 case). Most patients $(71 \%, \mathrm{n}=5,037)$ used one or more DMARD concomitantly with ETN, and $52.7 \%$ of patients $(\mathrm{n}=3,736)$ received MTX. Most patients $(75 \%, \mathrm{n}=5,317)$ received concomitant corticosteroids. A medical history of TB was present in 453 patients $(6.5 \%)$, of whom 98\% $(n=444)$ received chemoprophylaxis for TB (isoniazid; INH). Nearly every patient $(98.5 \%, \mathrm{n}=6,988)$ received a chest radiograph, and $93.8 \%(\mathrm{n}=6,649)$ received tuberculin tests. 
Table 1. Characteristics of patients participating in postmarketing surveillance of etanercept (ETN) in Japan.

\begin{tabular}{|c|c|}
\hline Characteristic & $\begin{array}{l}\text { ETN Cases, } \\
\mathrm{n}(\%)\end{array}$ \\
\hline Male/female & $1345 / 5746(19.0 / 81.0)$ \\
\hline Age, yrs, $15-19,20-29,30-39,40-49,50-59,60-69, \geq 70$ & $\begin{array}{c}32(0.5), 190(2.7), 468(6.6), 801(11.3) \\
1983(28.0), 2212(31.2), 1405(19.8)\end{array}$ \\
\hline Mean weight, $\mathrm{kg}$ (range) & $53.3(27-130)$ \\
\hline Steinbrocker* stage: I, II, III, IV & $368(5.2), 1551$ (21.9), 2598 (36.7), 2567 (36.2) \\
\hline Steinbrocker* function: I, II, III, IV & 498 (7.0), 3984 (56.2) 2343 (33.1), 259 (3.7) \\
\hline History of tuberculosis: yes & $453^{\dagger \dagger}(6.5)$ \\
\hline Comorbidities: yes & $4128(58.2)$ \\
\hline History of smoking: yes & $1030(16.5)$ \\
\hline History of steroid use: yes & $6066(88.1)$ \\
\hline \multicolumn{2}{|l|}{ No. patients receiving } \\
\hline Chest radiographs & $6988(98.5)$ \\
\hline Tuberculin tests & $6649(93.8)$ \\
\hline \multicolumn{2}{|l|}{ Dose of $\mathrm{ETN}^{\dagger}$ administered to patients, no. of patients (\%) } \\
\hline $50 \mathrm{mg}$ & $5866(82.7)$ \\
\hline $20 \mathrm{mg}$ & $14(0.2)$ \\
\hline $20-50 \mathrm{mg}$ & $1077(15.2)$ \\
\hline Concomitant use of DMARD: yes & $5037(71.0)$ \\
\hline No. concomitant DMARD: 1/2/3/4 & $3758 / 1117 / 144 / 18(53.0 / 15.8 / 2.0 / 0.3)$ \\
\hline \multicolumn{2}{|l|}{ Dose of MTX } \\
\hline No MTX & $3355(47.3)$ \\
\hline$<6 \mathrm{mg}$ & $1076(15.3)$ \\
\hline$\geq 6 \mathrm{mg} \leq 8 \mathrm{mg}$ & $1273(18.0)$ \\
\hline$>8 \mathrm{mg}$ & $1387(19.6)$ \\
\hline Concomitant use of steroid: yes & $5317(75.0)$ \\
\hline History of infliximab use: yes & $808(11.4)$ \\
\hline
\end{tabular}

DMARD: disease modifying antirheumatic drug; MTX: methotrexate. * A system to define RA, classify the stages of RA progression, criteria for therapeutic response of RA disease activity, and classification of functional impairment ${ }^{8} .{ }^{\dagger}$ Dose and administration in Japanese labeling is 10 to $25 \mathrm{mg} \times 2$ per week. ${ }^{\dagger \dagger} 444(98 \%)$ received chemoprophylaxis (isoniazid).

These results suggest that the PMS program successfully encouraged physicians to conduct the appropriate screening and chemoprophylaxis for TB before starting ETN. The ETN dose regimen received most often by patients $(82.7 \%$, $\mathrm{n}=5,866)$ was $50 \mathrm{mg}$ per week ( $25 \mathrm{mg} \times 2$ doses); 808 patients $(11.4 \%)$ had previous treatment with infliximab.

Safety. All 7,091 cases were included in safety analyses. Data collected for AE and ADR, coded using preferred terms from MedDRA, showed that the incidence of any AE or ADR was $35.3 \%(n=2,506)$ and $30.6 \%(n=2,173)$, respectively (Table $2 \mathrm{~A}$ ). Type and incidence of frequently observed $\mathrm{AE}$ or ADR are shown in Tables $2 \mathrm{~B}$ and $2 \mathrm{C}$. Injection site reaction was the most frequently observed $\mathrm{AE}$ $(5.3 \%, \mathrm{n}=377)$, followed by rash $(3.2 \%, \mathrm{n}=228)$ and pyrexia $(2.4 \%, \mathrm{n}=169$; Table $2 \mathrm{~B})$. The incidence of serious $\mathrm{AE}$ and serious $\mathrm{ADR}$ were $7.5 \%(\mathrm{n}=535)$ and $5.7 \%(\mathrm{n}=$ 403), respectively (Table 2A). The most frequent serious AE was pneumonia $(0.8 \%, \mathrm{n}=59)$ followed by interstitial lung disease $(0.6 \%, \mathrm{n}=42$; Table $2 \mathrm{C})$. Specifically important ADR for patients with RA, especially while being treated with TNF inhibitors, are summarized in Table 3. Ten suspected TB cases were reported during the 24 -week observation period. Of these 10 cases, 8 were confirmed as TB through at least 1 positive result by microscopic evaluation, polymerase chain reaction test, or culture. In 2 of the 8 confirmed cases, prophylactic INH had been received when ETN was started; retrospective evaluation suggested the existence of active TB at the onset of ETN treatment. Of the remaining 6 confirmed cases, prophylactic INH was not used prior to or during ETN treatment.

Fourteen cases of malignancy were reported during the observation period, which included 3 cases of lymphoma and 11 cases of malignant tumors. The average period between detection of malignancy and starting ETN was 82.1 days. Comments from the reporting physicians suggested that 8 out of 14 cases might have had preexisting malignancy when ETN was started. Two cases of congestive heart failure and one lupus-like syndrome were reported in this survey. There was no report of demyelinating disease. Among 7,091 patients, there were 29 deaths during the observation period of 24 weeks.

Continuation of etanercept. A total of 1,250 (17.6\%) patients discontinued ETN during the observational period (Table 4). The percentage of patients continuing treatment declined from $96.0 \%$ after 4 weeks to $82.4 \%$ after 24 weeks (Figure 1). The primary reason for stopping treatment (Table 
Table 2A. Total number of adverse events and adverse drug reactions with etanercept.

\begin{tabular}{|c|c|c|}
\hline & \multicolumn{2}{|c|}{ Etanercept All Cases $(\mathrm{n}=7091)$} \\
\hline & $\begin{array}{l}\text { Adverse } \\
\text { Events, } \\
\mathrm{n}(\%)\end{array}$ & $\begin{array}{c}\text { Adverse Drug } \\
\text { Reactions, } \\
\text { n }(\%)\end{array}$ \\
\hline Total & $2506(35.3)$ & $2173(30.6)$ \\
\hline Serious & $535(7.5)$ & $403(5.7)$ \\
\hline
\end{tabular}

Table $2 B$. Incidence of frequently observed adverse events with etanercept.

\begin{tabular}{lc}
\hline Adverse Event & $\mathrm{n}(\%)$ \\
\hline Injection site reaction & $377(5.3)$ \\
Rash & $228(3.2)$ \\
Pyrexia & $169(2.4)$ \\
Abnormal hepatic function & $167(2.4)$ \\
Nasopharyngitis & $158(2.2)$ \\
Pruritis & $126(1.8)$ \\
Upper respiratory tract infection & $125(1.8)$ \\
Pneumonia & $88(1.2)$ \\
Erythema & $85(1.2)$ \\
Herpes zoster & $71(1.0)$
\end{tabular}

Table 2C. Incidence of frequently observed serious adverse events with etanercept.

\begin{tabular}{ll}
\hline Serious Adverse Event & $\mathrm{n}(\%)$ \\
\hline Pneumonia & $59(0.8)$ \\
Interstitial lung disease & $42(0.6)$ \\
Pyrexia & $27(0.4)$ \\
Sepsis & $20(0.3)$ \\
Herpes zoster & $17(0.2)$ \\
Pneumocystis jiroveci pneumonia & $15(0.2)$ \\
Urinary tract infection & $13(0.2)$ \\
Cellulitis & $10(0.1)$ \\
Bacterial arthritis & $10(0.1)$ \\
Femoral neck fracture & $10(0.1)$ \\
\hline
\end{tabular}

4) was $\mathrm{AE}(8.6 \%, \mathrm{n}=613)$, followed by lack of effectiveness $(2.7 \%, \mathrm{n}=189)$ and by patients stopping their visits or moving to another hospital $(2.4 \%, \mathrm{n}=169)$.

Kaplan-Meier analysis for cumulative rate of $A E$ and $A D R$. A Kaplan-Meier analysis was performed (Figure 2) to evaluate the cumulative rate of AE and ADR. The occurrence rates of $\mathrm{AE}$ and $\mathrm{ADR}$ increased in a similar fashion until roughly Day 30. They continued to increase slowly until Day 180 . Results also demonstrated that approximately $50 \%$ of ADR occurred within 8 weeks of initiating ETN.

Effectiveness. Of 7,091 cases, effectiveness was evaluated with 6,563 cases; 528 cases were excluded due to lack of assessable data $(n=478)$, too short treatment period $(<2$ weeks; $\mathrm{n}=25$ ), etc. Several different measures including DAS28 were used to assess treatment effectiveness (Table 5). The evaluated number of each measure is shown in Table 5. The baseline average DAS28 score was 6.0; this reduced to 4.4 (27\% improvement) within 4 weeks and further to 3.9
Table 3. Incidence of specifically important adverse drug reactions in patients participating in postmarketing surveillance of etanercept in Japan.

\begin{tabular}{lc}
\hline Adverse Drug Reactions & $\begin{array}{c}\text { Etanercept } \\
\mathrm{n}(\%)\end{array}$ \\
\hline Total pneumonia* & $102(1.4)$ \\
Pneumocystis jiroveci pneumonia & $16(0.2)$ \\
Tuberculosis ${ }^{\dagger}$ & $10(0.1)$ \\
Pulmonary & $8(0.1)$ \\
Extrapulmonary ${ }^{\dagger \dagger}$ & $2(0.03)$ \\
Interstitial lung disease & $44(0.6)$ \\
Malignancy & $14(0.2)$ \\
Demyelinating disease & $0(0)$ \\
Congestive heart failure & $2(0.03)$ \\
Lupus-like syndrome & $1(0.01)$ \\
\hline
\end{tabular}

* Total pneumonia $=$ pneumonia $(\mathrm{n}=80)$, bacterial pneumonia $(9)$, bronchopneumonia (6), chlamydia pneumonia (4), staphylococcal pneumonia (1), candida pneumonia (1), fungal pneumonia (1). One case developed both pneumonia and bronchopneumonia. $\dagger 2$ indefinite cases. $\dagger$ Tuberculous abscess (thigh) + gastrointestinal tuberculosis.

Table 4. Discontinuation of etanercept treatment.

\begin{tabular}{lc}
\hline Total no. patients who discontinued treatment $(\%)$ & $1250(17.6)$ \\
Period until discontinuing ETN, days & $73.4( \pm 48.5)$ \\
Reason for discontinuation, n (\%) & \\
Adverse events & $613(8.6)$ \\
No effectiveness & $189(2.7)$ \\
Patient stopped visiting hospital/moved to another hospital & $169(2.4)$ \\
Other & $142(2.0)$ \\
Refused treatment for economic reasons & $116(1.6)$ \\
Achieved goal of treatment & $21(0.3)$ \\
\hline ETN: etanercept. &
\end{tabular}

(35\% improvement) within 24 weeks of starting treatment $(\mathrm{p}<0.001)$. The average duration of morning stiffness was 111.5 minutes at baseline, which declined to 44.3 minutes (60\% improvement) within 4 weeks and to 31 minutes (72\% improvement) within 24 weeks $(\mathrm{p}<0.001)$. The number of tender joints $(9.9 ; 4.5 ; 3.3)$ or swollen joints $(9.1 ; 4.3 ; 3.0)$ and the visual analog scale score for pain $(60.9 \mathrm{~mm} ; 37.2$ $\mathrm{mm} ; 31.3 \mathrm{~mm}$ ) also decreased significantly from baseline to Weeks 4 and 24, respectively. Baseline ESR value was significantly reduced from 61.1 to $39.3 \mathrm{~mm} / \mathrm{h}$ (36\% improvement) after 4 weeks and dropped to $37.1 \mathrm{~mm} / \mathrm{h}(39 \%$ improvement) after 24 weeks ( $<0.001$ ), while the baseline CRP value of $3.78 \mathrm{mg} / \mathrm{dl}$ dropped to $1.39 \mathrm{mg} / \mathrm{dl}(63 \%$ improvement) after 4 weeks and to $1.33 \mathrm{mg} / \mathrm{dl}(65 \%$ improvement) after 24 weeks ( $<<0.001)$. Using EULAR response criteria, 1,780 out of 2,337 cases $(76.2 \%)$ experienced a moderate or good response after Week 4; this improved to 3,268 out of 3,887 cases $(84.1 \%)$ after 24 weeks (Figure 3). Positive response was greater among patients with concomitant use of MTX (Figure 4), and better effectiveness was observed with increasing MTX dose. For 411 patients previously treated with infliximab, 25.3\% 


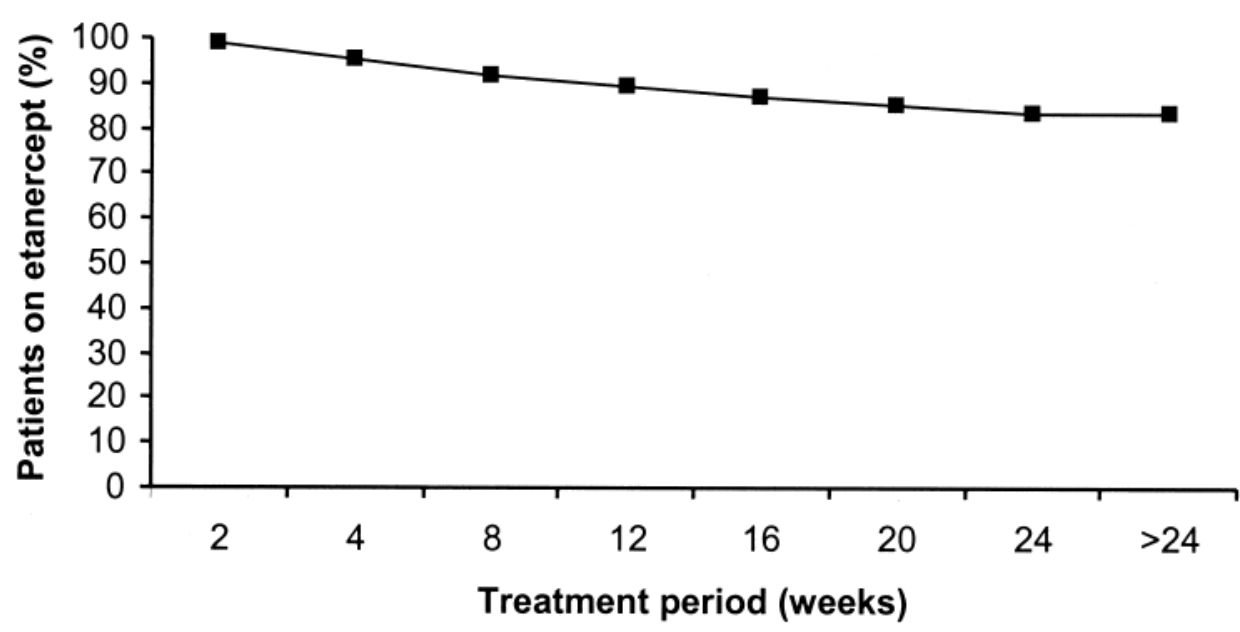

Figure 1. Continuation rate of patients taking etanercept.

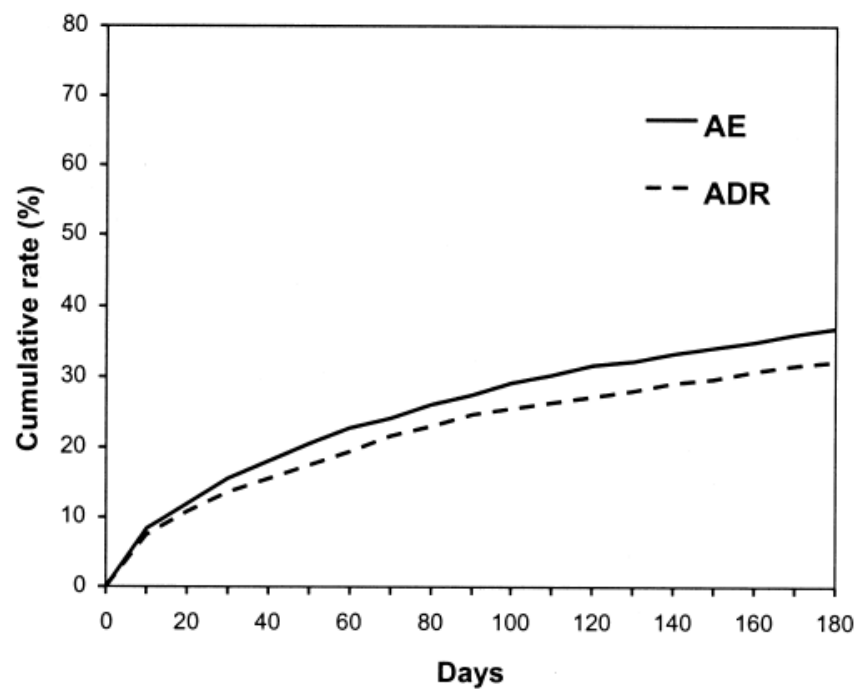

Figure 2. Kaplan-Meier analysis for cumulative rate of adverse events (AE) and adverse drug reactions (ADR) in patients taking etanercept.

$(\mathrm{n}=104)$ achieved a good response while $59.6 \%(\mathrm{n}=245)$ achieved a moderate response (Figure 5).

\section{DISCUSSION}

This comprehensive PMS study followed all patients with RA treated with ETN in Japan. It was conducted in accord with the guidelines and instruction of the Japanese health authorities. Data monitoring and recording were achieved as originally planned, and all case report forms for the first 7,091 patients were collected successfully.

This study provides important information regarding real-world patient usage patterns of ETN. Given that several studies suggest that the outcome of DMARD treatment for RA may be better if it is initiated early in the course of the disease $\mathrm{e}^{13-15}$, studying the characteristics of patients registered in this PMS is useful. Results showed that $51 \%$ were age 60 years and older, 72\% had advanced RA (Steinbrocker stage III and IV), and 58.2\% had comorbidities. This emphasizes that positive results were also observed in the population despite starting treatment relatively late in the disease process. The overall safety and effectiveness profile in this PMS demonstrated excellent effectiveness and tolerability of ETN among Japanese patients with RA; however, additional subanalyses based on age, duration of RA, and Steinbrocker stage may reveal features that will allow targeting treatment for optimal safety and effectiveness.

Most AE observed during this study were not serious, and the incidence of serious AE (7.54\%) was similar to that observed in clinical trials involving ETN $\left(5 \%{ }^{16}, 7 \%^{17}\right.$, and $\left.11 \%^{18}\right)$. This surveillance showed that the most commonly observed AE was injection site reactions (5.3\%), and the most frequently observed serious $\mathrm{AE}$ was pneumonia $(0.8 \%)$. The second most common serious AE was interstitial pneumonia. Multiple underlying factors can cause interstitial lung disease among RA patients, including underlying RA, concomitant use of DMARD, and opportunistic infection such as cytomegalovirus. However, there was no further information to identify the cause in this survey; additional investigation is required for further analysis. As in clinical trials, these results indicate that ETN was well tolerated for 24 weeks in Japanese patients treated in a real-world setting.

There have been reports about activation of latent TB by TNF inhibitors ${ }^{19-22}$. The incidence of TB in Japan is estimated at 28/100,000 and in the US at 5/100,00023. One of the key objectives of this PMS was to promote the appropriate screening and prophylaxis of TB for RA patients starting ETN because Japan is a region endemic for TB. The Japan College of Rheumatology published guidelines for screening for latent TB before initiation of TNF inhibitor and recommended the use of prophylactic INH if necessary ${ }^{23}$.

The PMS interim results demonstrated that a very high percentage of ETN patients $(98.5 \%)$ were screened for TB 
Table 5. Measures of effectiveness in patients participating in postmarketing surveillance of etanercept in Japan.

\begin{tabular}{lccc}
\hline & \multicolumn{3}{c}{ Period After Treatment Initiation, weeks } \\
Effectiveness Measure, mean (SD) & Baseline & $4 *$ & 24* \\
\hline DAS28 score & $6.0(1.2)$ & $4.4(1.3)$ & $3.9(1.3)$ \\
$\mathrm{n}$ & 4643 & 2511 & 4248 \\
No. tender joints & $9.9(7.1)$ & $4.5(5.1)$ & $3.3(4.4)$ \\
$\mathrm{n}$ & 6425 & 4010 & 6229 \\
No. swollen joints & $9.1(6.3)$ & $4.3(4.5)$ & $3.0(3.7)$ \\
$\mathrm{n}$ & 6425 & 4009 & 6227 \\
Visual analog scale score, mm & $60.9(22.4)$ & $37.2(22.6)$ & $31.3(22.5)$ \\
$\mathrm{n}$ & 5876 & 3420 & 5464 \\
ESR, mm/h & $61.1(33.2)$ & $39.3(28.1)$ & $37.1(28.3)$ \\
$\mathrm{n}$ & 5059 & 3024 & 4923 \\
CRP, mg/dl & $3.8(3.4)$ & $1.4(2.1)$ & $1.3(2.2)$ \\
$\mathrm{n}$ & 6399 & 4221 & 6427 \\
Duration of morning stiffness, min & $111.5(181.7)$ & $44.3(114.4)$ & $31.0(90.3)$ \\
$\mathrm{n}$ & 5797 & 3169 & 4988 \\
\hline
\end{tabular}

CRP: C-reactive protein; DAS: Disease Activity Score; ESR: erythrocyte sedimentation rate. * All different compared to baseline, $\mathrm{p}<0.001$.

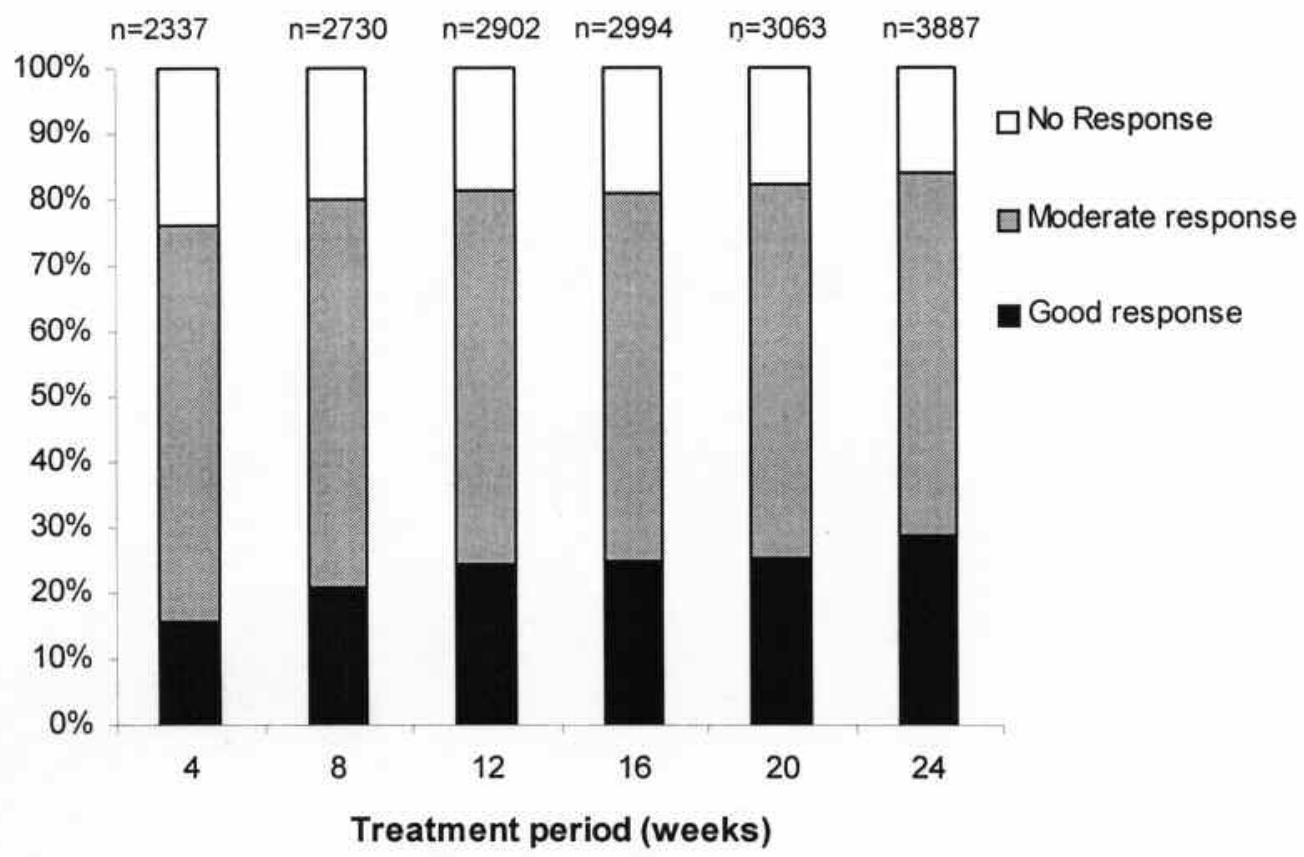

Figure 3. Effectiveness of etanercept in patients for the first 24 weeks as indicated by EULAR response rate, using DAS28 (last observation carried forward).

by chest radiograph. Ten cases, including 2 unconfirmed cases, were reported as TB in this PMS. Two cases developed TB despite the use of INH, with retrospective analysis suggesting active TB at onset of ETN. The remaining 6 confirmed cases did not receive prophylactic INH. In this interim analysis, 453 patients $(6.5 \%)$ out of 7,099 cases had a medical history of TB, and 444 of them (98\%) were treated with prophylactic INH. Reactivation of latent TB was not observed among patients who had appropriate screening and received prophylactic INH. The interim results of this PMS suggest that careful screening is important to avoid the use of TNF inhibitors in those with active TB, and that prophylactic INH appears to be effective when prescribed for suspected latent TB.

Increased risk of certain types of malignancy, such as lymphoma, is reported in patients with RA. However, the association of TNF inhibitors and risk of malignancy is still uncertain $^{24-26}$. Although 14 cases of malignancy were reported during the 24-week observation period in this PMS, it is difficult to estimate if the number is high or low as there 


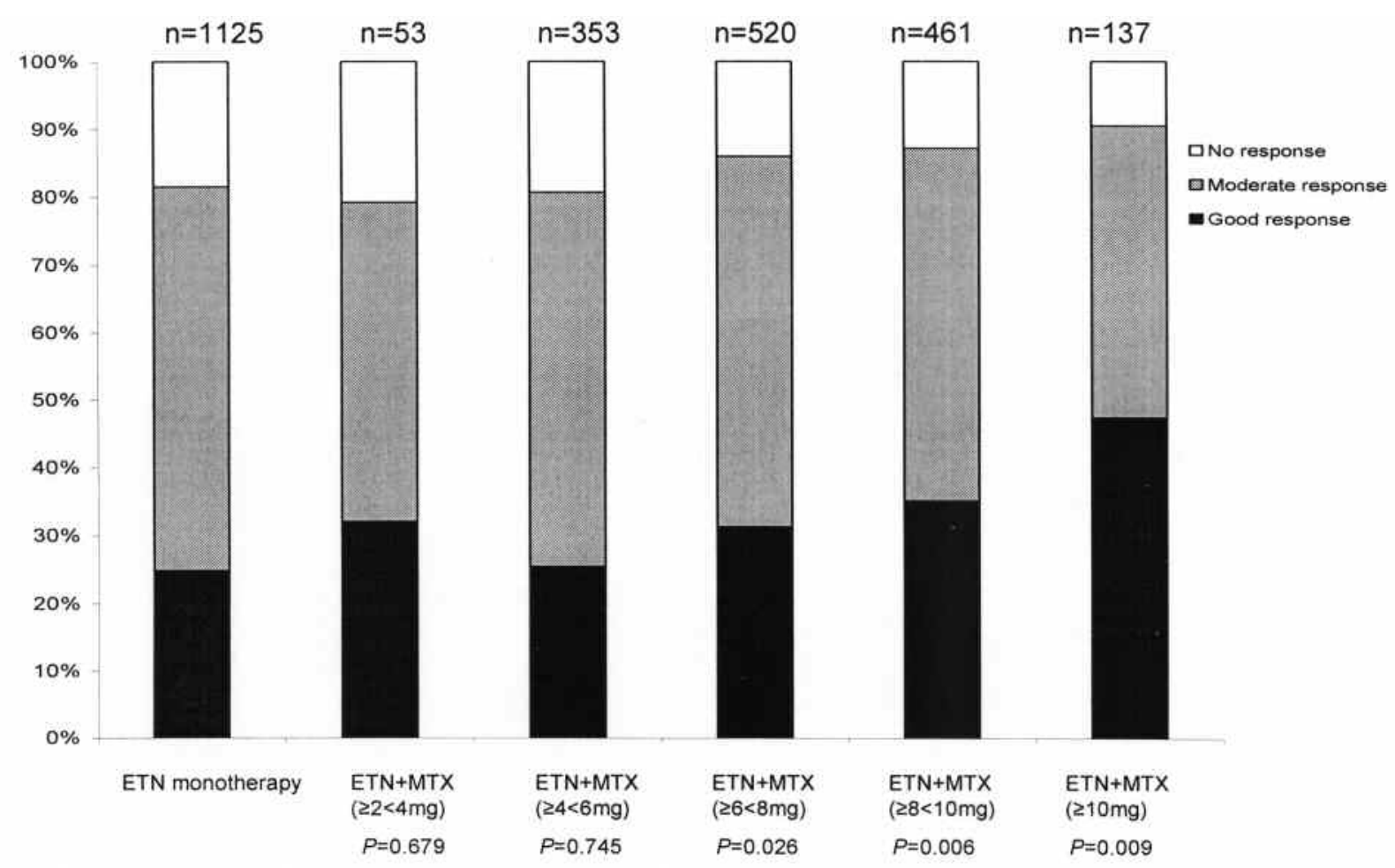

Figure 4. Effectiveness of etanercept (ETN) for the first 24 weeks in patients receiving ETN monotherapy or ETN plus methotrexate (MTX), as indicated by EULAR response criteria using DAS28 (last observation carried forward). Total number of ETN + MTX cases = 1,526. Two cases were ETN + MTX $(<2 \mathrm{mg} / \mathrm{wk})$; one case was classified as good response, the other as moderate response. Response rate was compared with that of ETN monotherapy by chi-square test. Trend on response rate evaluated by Cochran-Armitage test; result was significant $(\mathrm{p}<0.001)$.

is no appropriate control regarding the incidence of malignancy among Japanese with RA. It is also possible that malignancy might have already existed in some cases prior to initiation of ETN. Careful interview and screening of patients, if necessary, may provide information for physicians to evaluate risk and benefit of ETN for patients who are at risk of having malignancy.

Japanese guidelines for use of TNF inhibitor in RA indicate the use of biologics when patients have not responded to at least one DMARD. During this study, $84.1 \%$ of patients experienced a good or moderate EULAR response, a very positive result for patients not benefiting from previous treatments.

Patients who were prescribed higher doses of MTX concomitantly with ETN in this study showed a higher percentage of patients achieving a better response. Since the upper dose of MTX used in Japan is limited to $8 \mathrm{mg}$ per week, much lower than that used in the US or Europe (5 mg to 20 mg per week), it may be possible that an even greater proportion of patients could achieve a good response if the MTX dose were increased.

From evaluation of 411 patients who had a history of infliximab use, $84.9 \%$ experienced a good or moderate EULAR response. This result suggests that, for patients who do not respond to or discontinue infliximab treatment, switching to ETN may be helpful in controlling disease activity, as reported elsewhere ${ }^{23}$.

This PMS study was designed to evaluate the risks and benefits of ETN, a newly introduced product in Japanese medical practice. As a result of the excellent benefit/risk profile of ETN demonstrated in this interim report of real-world practice, restrictions on the use of ETN in Japan have been lifted. The final results will be evaluated for the entire population of registered patients when these data are available.

Interpretation of this large study is limited by the fact that there was no control population. Thus, it is difficult to discriminate patient outcomes caused by ETN from outcomes caused by other factors, such as the natural history of the disease, observer or patient expectations, or other treatments. Safety data were collected from all 7,091 cases, but there are missing data on effectiveness. Nonetheless, it does provide insight on the use of ETN in a large cohort of patients being treated in real-world settings.

This surveillance study has produced one of the largest observational databases available worldwide for patients with RA treated with biologics. It registered all patients with RA treated with ETN in Japan, and systematically gathered safety and effectiveness data. This interim analysis of over 7,000 patients provides useful data about real-world ETN

Personal non-commercial use only. The Journal of Rheumatology Copyright $\odot$ 2009. All rights reserved. 


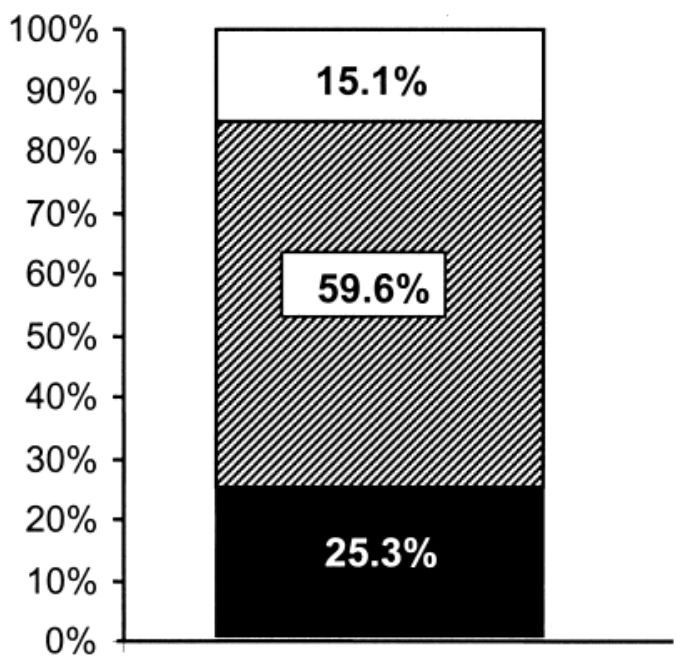

Treatment period 24 weeks

\section{No response}

\section{Q Moderate response}

- Good response

Figure 5. Effectiveness of etanercept for the first 24 weeks as indicated by response rate in patients switching from infliximab to etanercept $(n=411)$, based on EULAR response criteria using DAS28 (last observation carried forward).

use and supports the safety and effectiveness of ETN as a treatment for Japanese with RA. Additional analyses of data from this study may identify factors that influence safety and effectiveness of ETN and further assist in defining its appropriate use.

\section{ACKNOWLEDGMENT}

The authors thank all participating physicians and registered patients. Dr. Urashima is acknowledged for conducting independent statistical analyses. This report was prepared with the assistance of Joanne Foehl (Wyeth Research, Global Medical Affairs) and BioMedCom Consultants Inc., Montreal, Canada.

Disclosures. Pursuant to the Pharmaceutical Affairs Law of Japan and the regulations promulgated thereunder, the sponsor (Wyeth) was required to conduct a postmarketing surveillance program as a condition for the marketing approval of etanercept. Wyeth was responsible for the development of the study protocol (with instruction from the Pharmaceutical and Medical Device Agency and advice from the Japan College of Rheumatology Etanercept Post-Marketing Surveillance Committee) and for the initial analysis of the data.

Financial support: T. Koike, M. Harigai, S. Inokuma, K. Inoue, N. Ishiguro, J. Ryu, T. Takeuchi, Y. Tanaka, and H. Yamanaka are all members of the Entanercept Post-Marketing Surveillance Committee of the Japan College of Rheumatology. The Committee was created in response to a request for assistance from the Ministry of Health, Labor and Welfare (MLHW) of Japan. The role of the committee is to provide independent advice to Wyeth K.K. on conducting the post-marketing surveillance (PMS) program mandated by MHLW and on the results thereof. Participation on this committee is not compensated. It is the belief of the first author that this position does not constitute a conflict of interest. The doctors participated in the review and analysis of the PMS data in their capacity as committee members and are so listed. Financial relationships of authors with all manufacturers of biological products used in the management of RA are as follows (1: research grant to the institute to which they are affiliated; 2 : consulting fee; 3: speakers' bureau; 4: fulltime employee. T. Koike: Abbott Japan, 1; Chugai Pharmaceutical Co. Ltd., 1; Eisai Co. Ltd., 1; Mitsubishi Tanabe Pharma, 1; Takeda Pharmaceutical Co. Ltd., 1; Wyeth KK, 1; Abbott Japan, 3; Chugai Pharmaceutical Co. Ltd., 3; Eisai Co. Ltd., 3; Mitsubishi Tanabe Pharma, 3; Takeda Pharmaceutical Co. Ltd., 3; Wyeth KK, 3. M. Harigai: Abbott Japan, 1; Chugai Pharmaceutical Co. Ltd., 1; Eisai Co. Ltd., 1; Mitsubishi Tanabe Pharma, 1; Takeda Pharmaceutical Co. Ltd., 1; Wyeth KK, 1, Abbott Japan, 3; Chugai Pharmaceutical Co. Ltd., 3; Eisai Co. Ltd., 3; Mitsubishi Tanabe Pharma, 3; Takeda Pharmaceutical Co. Ltd., 3; Wyeth KK, 3. S. Inokuma: Chugai Pharmaceutical Co. Ltd., 3; Eisai Co. Ltd., 3; Mitsubishi Tanabe Pharma, 3; Takeda Pharmaceutical Co. Ltd., 3; Wyeth KK, 3. K. Inoue: Takeda Pharmaceutical Co. Ltd., 1; Wyeth KK, 1; Abbott Japan, 3; Chugai Pharmaceutical Co. Ltd., 3; Eisai Co. Ltd., 1; Mitsubishi Tanabe Pharma, 1; Eisai Co. Ltd., 3; Mitsubishi Tanabe Pharma, 3; Takeda Pharmaceutical Co. Ltd., 3; Wyeth KK, 3. N. Ishiguro: Chugai Pharmaceutical Co. Ltd., 1; Eisai Co. Ltd., 1; Mitsubishi Tanabe Pharma, 1; Takeda Pharmaceutical Co. Ltd., 1; Wyeth KK, 1; Chugai Pharmaceutical Co. Ltd., 3; Eisai Co. Ltd., 3; Mitsubishi Tanabe Pharma, 3; Takeda Pharmaceutical Co. Ltd., 3; Wyeth KK, 3. J. Ryu: Eisai Co. Ltd., 1; Chugai Pharmaceutical Co. Ltd., 1; Wyeth KK, 1; Eisai Co. Ltd., 3; Wyeth KK, 3. T. Takeuchi: Mitsubishi Tanabe Pharma, 3; Wyeth KK, 3. Y. Tanaka: Mitsubishi Tanabe Pharma, 2: Mitsubishi Tanabe Pharma, 3; Takeda Pharmaceutical Co. Ltd., 3; Wyeth KK, 3. H. Yamanaka: Chugai Pharmaceutical Co. Ltd., 1; Abbott Japan, 1; Eisai Co. Ltd., 1; Mitsubishi Tanabe Pharma, 1; Takeda Pharmaceutical Co. Ltd., 1; Wyeth KK, 1; Chugai Pharmaceutical Co. Ltd., 2; Wyeth, 2; Abbott Japan, 3; Chugai Pharmaceutical Co. Ltd., 3; Eisai Co. Ltd., 3; Mitsubishi Tanabe Pharma, 3; Takeda Pharmaceutical Co. Ltd, 3; Wyeth KK, 3. B. Freundlich: Wyeth Research, 4. K. Fujii, Wyeth KK, 4. M. Suzukawa: Wyeth KK, 4.

\section{REFERENCES}

1. U.S. Food and Drug Administration. MEDWatch Program. [Internet. Accessed February 6, 2009.] Available from: http://www.fda.gov/cder/handbook/medwatch.htm

2. Carleton B, Foerster V, Warren L, Smith MA. Post-marketing pharmaco-surveillance in Canada. Health Canada website. [Internet. Accessed February 6, 2009.] Available from: http://www.hc-sc.gc.ca/hcs-sss/alt_formats/hpb-dgps/pdf/pharma/ ref-can_e.pdf

3. Furst DE, Breedveld FC, Kalden JR, et al. Updated consensus statement on biological agents for the treatment of rheumatoid arthritis and other rheumatic diseases (May 2002). Ann Rheum Dis 2002;61 Suppl 2:ii2-ii7.

4. Ledingham J, Deighton C. Update on the British Society for Rheumatology guidelines for prescribing TNF-alpha blockers in adults with rheumatoid arthritis (update of previous guidelines of April 2001). Rheumatology 2005;44:157-63.

5. Genovese MC, Bathon JM, Martin RW, et al. Etanercept versus methotrexate in patients with early rheumatoid arthritis: two-year radiographic and clinical outcomes. Arthritis Rheum 2002;46:1443-50.

6. Innovations Report. Half of patients with active early rheumatoid arthritis achieved clinical remission. Innovations Report website [Internet. Accessed February 6, 2009.] Available from: http://www.innovationsreport.com/html/reports/medicine_health/ report-95903.html

7. Japan College of Rheumatology. Introducing Japan College of Rheumatology (JCR). Japan College of Rheumatology website [Internet. Accessed February 6, 2009.] Available from: http://www.ryumachi-jp.com/english/index.html

8. Steinbrocker O, Traeger $\mathrm{CH}$, Batterman RC. Therapeutic criteria in Personal non-commercial use only. The Journal of Rheumatology Copyright @ @ 2009. All rights reserved. 
rheumatoid arthritis. JAMA 1949;140:659-62.

9. Northrup Grumman Corporation. MedDRA and the MSSO. Northrup Grumman Corporation website [Internet. Accessed February 6, 2009.] Available from: http://www.meddramsso.com/MSSOWeb/index.htm

10. ICH Steering Committee. ICH Harmonised Tripartite Guideline Clinical safety data management: definitions and standards for expedited reporting. Pharmaceuticals and Medical Devices Agency website [Internet. Accessed February 6, 2009.] Available from: http://www.pmda.go.jp/ich/e/e2a_95_3_20e.pdf

11. van Gestel AM, Prevoo ML, van 't Hof MA, van Rijswijk MH, van de Putte LB, van Riel PL. Development and validation of the European League Against Rheumatism response criteria for rheumatoid arthritis. Comparison with the preliminary American College of Rheumatology and the World Health Organization/International League Against Rheumatism criteria. Arthritis Rheum 1996;39:34-40.

12. Prevoo ML, van 't Hof MA, Kuper HH, van Leeuwen MA, van de Putte LB, van Riel PL. Modified disease activity scores that include twenty-eight-joint counts. Development and validation in a prospective longitudinal study of patients with rheumatoid arthritis. Arthritis Rheum 1995;38:44-8.

13. American College of Rheumatology Subcommittee on Rheumatoid Arthritis Guidelines. Guidelines for the management of rheumatoid arthritis: 2002 Update. Arthritis Rheum 2002;46:328-46.

14. Bernatsky S, Feldman D, Shrier I, et al. Care pathways in early rheumatoid arthritis. Can Fam Physician 2006;52:1444-5.

15. Donahue KE, Gartlehner G, Jonas DE, et al. Systematic review: Comparative effectiveness and harms of disease-modifying medications for rheumatoid arthritis. Ann Intern Med 2007;124-34.

16. van Riel PL, Taggart AJ, Sany J, et al. Efficacy and safety of combination etanercept and methotrexate versus etanercept alone in patients with rheumatoid arthritis with an inadequate response to methotrexate: The ADORE study. Ann Rheum Dis 2006;65:1478-83.
17. Keystone EC, Schiff MH, Kremer JM, et al. Once-weekly administration of $50 \mathrm{mg}$ etanercept in patients with active rheumatoid arthritis: results of a multicenter, randomized, double-blind, placebo-controlled trial. Arthritis Rheum 2004;50:353-63.

18. Klareskog L, van der Heijde D, De Jager JP, et al. Therapeutic effect of the combination of etanercept and methotrexate compared with each treatment alone in patients with rheumatoid arthritis: double-blind randomised controlled trial. Lancet 2004;363:675-81.

19. Hamdi $\mathrm{H}$, Mariette $\mathrm{X}$, Godot $\mathrm{V}$, et al. Inhibition of anti-tuberculosis T-lymphocyte function with tumour necrosis factor antagonists. Arthritis Res Ther 2006;8:R114.

20. Botha T, Ryffel B. Reactivation of latent tuberculosis infection in TNF-deficient mice. J Immunol 2003;171:3110-8.

21. Desai SB, Furst DE. Problems encountered during anti-tumour necrosis factor therapy. Best Pract Res Clin Rheumatol 2006;20:757-90.

22. Long R, Gardam M. Tumour necrosis factor-alpha inhibitors and the reactivation of latent tuberculosis infection. CMAJ 2003;168:1153-6.

23. World Health Organization. Global tuberculosis control: surveillance, planning, financing: WHO Report 2007. World Health Organization website. [Internet. Accessed February 6, 2009.] Available from: http://www.who.int/tb/en/

24. Bathon JM, Martin RW, Fleischmann RM, et al. A comparison of etanercept and methotrexate in patients with early rheumatoid arthritis. N Engl J Med 2000;343:1586-93.

25. Jundt JW, Browne BA, Fiocco GP, Steele AD, Mock D. A comparison of low dose methotrexate bioavailability: oral solution, oral tablet, subcutaneous and intramuscular dosing. J Rheumatol 1993;20:1845-9.

26. van der Heijde D, Da Silva JC, Dougados M, et al. Once-weekly 50-mg dosing of Etanercept $\left(\right.$ Enbrel $\left.^{\circledR}\right)$ is as effective as 25-mg twice-weekly dosing in patients with ankylosing spondylitis. Ann Rheum Dis 2006;65:1572-7. 